\title{
Response to a change in transport noise exposure: Competing explanations of change effects
}

\author{
A. L. Brown ${ }^{\text {a) }}$ \\ Urban Research Program, Griffith School of Environment, Griffith University, Nathan, Brisbane, \\ Queensland 4111, Australia \\ Irene van Kamp ${ }^{\text {b) }}$ \\ Centre of Environmental Health Research, National Institute for Public Health and the Environment, \\ P.O. Box 1, 32700 BA Bilthoven, The Netherlands
}

(Received 21 April 2008; revised 24 September 2008; accepted 6 December 2008)

\begin{abstract}
Annoyance response to a change in noise exposure appears to demonstrate an excess response relative to those predicted from exposure-response curves obtained under steady-state conditions. This change effect also appears to persist well after the change. Numerous explanations have been postulated for this phenomenon. This paper catalogs the different explanations and reviews the evidence for each. The evidence is of limited and variable quality but, while inadequate to endorse any one explanation, is sufficient to reject some notions and to identify a residual set of plausible explanations. These include two explanations based on modifiers of exposure-response relationships that potentially change between before and after conditions, an explanation based on differential response criteria of respondents chronically exposed to different steady-state levels of noise, and an explanation based on retention of coping strategies. All have ramifications for the assessment of human response (annoyance) where noise exposure changes, and some have wider implications for the interpretation of generalized exposure-response curves obtained in the steady state.
\end{abstract}

(C) 2009 Acoustical Society of America. [DOI: 10.1121/1.3058636]

PACS number(s): 43.50.Qp, 43.66.Lj [BSF]

Pages: 905-914

\section{INTRODUCTION}

The literature of human response to a change in transport noise exposure suggests that human response to changed exposure includes both an exposure effect and a change effect. The change effect is manifest as an excess response to the new noise exposure over that predicted from steady-state exposure-response curves. Excess response was found unambiguously for changes in road traffic noise where the change in exposure resulted from an increment or decrement in source levels (termed type 1 changes) rather than from the insertion of barriers or other path mitigation interventions (type 2 changes) (Brown, 2009).

This paper catalogs the surprising number of putative explanations advanced for the phenomenon of change effect and reviews evidence for each of the explanations. For some of the explanations, this often required identification and, where possible, clarification of confusion and ambiguity in various concepts and terms found in the literature on response to change.

Why excess response has spawned so many alternative explanations is unclear, but given that situations where noise exposure changes as a result of infrastructure changes are contentious, explication of the change effect and its implications for assessing change is of practical importance to communities and authorities. Further, some have implications for

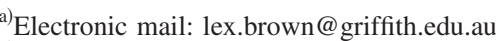

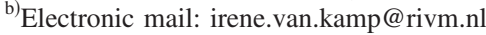

interpreting exposure-response relationships obtained under steady-state noise conditions. These need to be considered alongside other current debates concerning the durability of generalized exposure-response curves and assessing (trends in) annoyance (for example, Guski, 2004; Fidell and Silvati, 2004; van Kempen and van Kamp, 2005; Brooker, 2008).

\section{A. Explanations of the change effect}

The explanations of change effects are diverse. While we use the term "explanations," some are more appropriately seen as opinions. Others call on theory. Suggested explanations are discussed in Secs. II A-II K:

A. Any change effect is only transient as people adapt to the change.

B. Respondents' anticipation or expectation of change.

C. Respondents' attitudes toward the source/authorities change.

D. The combined effects of changes in other environmental attributes - an area effect or a halo effect, though we prefer the term surrogate effect.

E. Demand-response bias generated by repeated questioning of respondents.

F. Found in adaptation-level theory.

G. Partial retention of behavioral coping strategies.

H. Differential response criteria (response bias) in responding to annoyance scales.

I. Memory distortion.

J. Self-selection.

$\mathrm{K}$. While not explaining the change effect itself, perceptual 
constancy or loudness constancy may explain differences between type 1 and type 2 changes.

Below we examine the diverse claims and counterclaims for the different explanations and evidence from empirical studies and seek to clarify their underlying mechanisms.

\section{THE EXPLANATIONS}

\section{A. Any change effect is only transient as people adapt to the change}

There is a prevailing notion (part of the folklore of noise) that people adapt, habituate, or get used to new conditions after a change in exposure. There is confusion in the use of these terms. Habituation is a decrease in response to a stimulus after repeated presentations; adaptation an adjustment of response to a stimulus to reach a new equilibrium. In the literature of environmental noise, these terms have generally been applied without discrimination and without necessarily referring to component emotional, physiological, behavioral, and cognitive dimensions. Responses in change situations have been described as transient, and respondents assumed, in lay terms, to get used to the new conditions, but mechanisms for these processes/outcomes are not invoked. Desensitization of response to a noise stimulus (Raw and Griffiths, 1985) is another "adaptation-related" term and is included in several of the explanations described below. Weinstein (1982) used the antonym sensitization for an increase in response over time. ${ }^{1}$ Sensitization is an example of nonassociative learning in which the progressive amplification of a response follows repeated administrations of a stimulus (Bell et al., 1995). As an example of claims for adaptation to noise, Nimura et al. (1973) implied that it was adaptation nearer the longer established of two new Shinkansen rail lines that was responsible for a much lesser response beside an older line as against one opened more recently.

There is ambiguity in the way different authors define adaptation. Particular interest here is in whether there is adaptation of any observed change effect, and we use the definition in Horonjeff and Robert (1997). Figure 1 illustrates two hypothetical chronologies of response to a step increase in noise exposure. The change effect is the difference between the attitudinal response after the change and the longterm baseline response to the new after-change exposure conditions (expected from steady-state exposure-response curves). The solid-line trajectory illustrates adaptation of the change effect, with regression of response to the new baseline level for the postchange exposure. The broken line trajectory suggests a persistent change effect, with no long-term adaptation.

Weinstein (1982) found that after-change responses remained constant between 4 and 16 months after the change following a large increment in noise exposure (no examination for change effect). By contrast, Lambert et al. (1996) reported adaptation near a new TGV line, but their approach was to ask respondents if they had become used to the noise $3-4$ years after the line opened $(85 \%$ indicated that they had, $75 \%$ within 1 year). This implicitly defines adaptation as re-

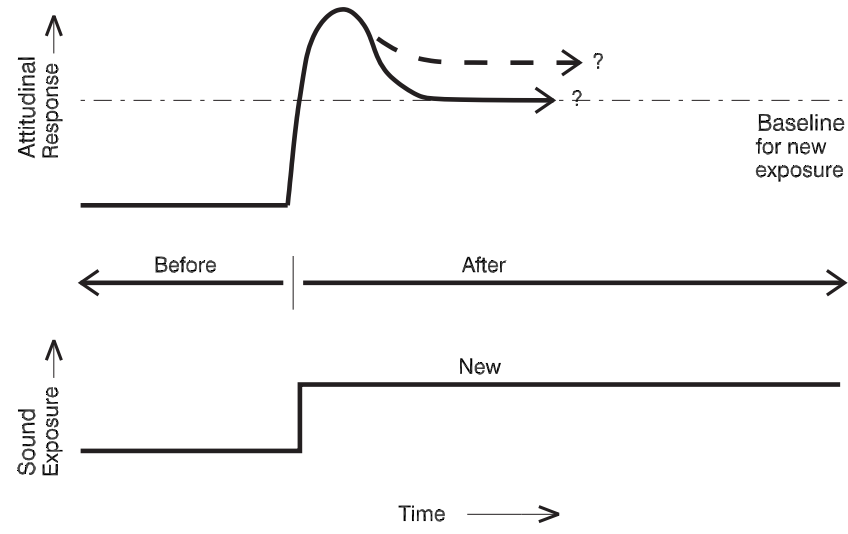

FIG. 1. Hypothetical chronologies of attitudinal response to a step-change in exposure. The light horizontal broken line is the expected response to the after-change conditions (from steady-state exposure-response curves). The two attitudinal response trajectories shown in bold are different possible responses to an increase in noise exposure (after Horonjeff and Robert, 1997).

sponses returning to the prechange conditions, not the expected postchange steady-state response as in Fig. 1. There is a related ambiguity in studies that use self-reported adaptation as, for example, in the study of Hatfield et al. (2001) on response to aircraft noise in Sydney where respondents were asked if they were more used to (24\% indicated that they were) or more sensitive to the noise. These very different definitions of adaptation are what Fields and Hall (1987) described as using the same label for measuring quite different concepts. The conclusion is that caution is required in synthesizing across different studies that reported that adaptation was/was not present.

The weight of evidence in empirical studies was that there is no adaptation of the change effect months, even years, after the change. Griffiths and Raw (1989) did find partial attenuation 7-9 years out, and Breugelmans et al. (2007) found that the change effect temporarily disappeared at the fifth of sixth resurveys of a panel around Schiphol but returned at the sixth resurvey. Most of the available results confirm the broken trajectory of Fig. 1 in the longer term. Could there be adaptation of at least part of the change effect immediately after the change, as suggested in Fig. 1? This has been postulated by various authors (Hatfield et al., 2001; Jonsson and Sörensen, 1973; Langdon and Griffiths, 1982; Lawson and Walters, 1973), but there is no empirical evidence of adaptation to the change effect in days or weeks following a change. Evidence of very rapid adaptation to noise, within hours and minutes, is primarily based on laboratory studies of perceptual change (e.g., Quehl and Basner, 2006), not field studies, but has no clear relevance in the current context. Overall, there is no evidence that the change effect is a transient phenomenon.

\section{B. Anticipation or expectation of change}

It is suggested that respondents' expectation (or anticipation) of change could explain the change effect. We note, at the outset, Guski's (1999) statement that, "There are no meaningful data on this topic." At issue is that the purported 
anticipation was sometimes merely assumed and that there is no standardization of what it is that respondents anticipate/ expect. Different concepts have been used: assumed expectation of increased annoyance (Öhrström, 1997; van Dongen and van den Berg, 1983), measurements variously operationalized as expectation of an improvement, deterioration, or remaining the same (Job et al., 1996), expected effect of a change (Mackie and Davies, 1981), and expectation of increased annoyance (Schreckenberg et al., 2001); and measurements, longitudinally, of expectation about future noise levels (Breugelmans et al., 2007). The assumption that all residents, living in an area that is known (by authorities, through the media, etc.) to be one in which noise will change, will share these expectations is open to question. Flindell and Witter (1999) provided evidence from Heathrow that a minority of respondents were actually aware of proposed changes despite prospective changes to aircraft flight patterns being extensively publicized.

Observations on the role of expectation in situations of change include the following: Öhrström (1997) speculated that expectation of an increase in annoyance could explain more annoyance before extension of a railway line than 3.5 years after; van Dongen and van den Berg (1983) suggested that expectations regarding a new railway line were the cause of before-change annoyance being higher than the actual annoyance levels afterward; Mackie and Davies (1981) provided empirical evidence that people expect changes to have more effect than they actually do; and Schreckenberg et al. (2001) reported that before a change, respondents' expectation of what annoyance would be after the change was higher than both before-change annoyance and after-change annoyance (actual change in noise levels proved to be zero). None of these observations shed any light on the role of expectation in explaining a change effect.

Recent evidence from Schiphol does not support this explanation; observed excess response in a subgroup experiencing an increase became apparent only after the new runway became fully operational despite prior extensive media coverage of this upcoming change (Breugelmans et al., 2007; Ministry of Transport, Public Works and Water Management, 2005). Repeat measurements of expectations regarding future noise levels (improvement versus deterioration) were also available in this study. Expectation of a deterioration was shown to be a strong predictor of annoyance (Houthuijs et al., 2007), but more detailed analyses would be needed to evaluate the precise influence of expectations (independently or via changed attitudes) on the measured change effect.

Based on the lack of other evidence and on the Schiphol study results, expectation per se has little support as direct explanation of the change effect. However, data from the Sydney Airport study (Job et al., 1996) do provide a potential link between expectation and another explanationchange in attitudes toward the authorities/source (see Sec. II C). If certain attitudes do change in situations where noise exposure changes, the role of expectation may partly be to shift the occurrence of attitudinal change, temporally, to before the change in exposure.

\section{Attitudes toward the source/authorities change}

A range of attitudes correlate with annoyance responses (Fields, 1993). This explanation postulates that certain attitudes (to authorities and to noise preventability) may change, becoming more negative where noise increases and more positive where noise levels decrease, thus modifying the exposure-effect relationship and resulting in the observed excess response in change studies (Job, 1988b). Langdon and Griffiths (1982) noted such a possibility for residents' perception of the public policy of authorities and that this possibility was first suggested by Scholes (1977). Fidell et al. (1985) suggested that heightened community awareness might plausibly be sufficient to account for a greater prevalence of self-reported annoyance.

Kastka (1981) could not attribute large excess response solely to the change in noise level, and based on no overall correlation between the magnitude of the reported effect at his 50 change sites and the change in levels at those sites, he suggests, though without evidence, that this may be due to goodwill to the authorities resulting from advertising campaigns for traffic calming schemes (also see Schreckenberg et al., 2001). Fields and Hall (1987) noted that there is some limited empirical evidence that attitudes of a population can be manipulated so as to alter annoyance responses. A more recent experiment (Djokvucic et al., 2004) indicates that (manipulated) attitude toward the source does indeed directly influence responses to noise independent of the noise effect. Performance impairment was shown to be indirectly influenced by (manipulated) attitude via reaction. Likewise, Maris et al. (2007) demonstrated that fairness of the exposure procedure (sound management) can be used as an instrument to reduce noise annoyance. Raw and Griffiths (1990) expressed a contrary view regarding the role of attitudes in the change effect, based on no observed differences in the exposure-response relationship for before conditions between their increase sites and decrease sites. They noted that it would also be necessary to assume that similar changes in attitude occurred in all of their field sites (with very different characteristics and histories), and these would have to be maintained for years after the change.

Is there evidence of attitudes toward the source/ authorities changing with a change in exposure and, if so, any evidence that these are linked to measured change effects? In attempting to address the first of these questions, Job et al. (1996) and, more recently, Schreckenberg and Meis (2007) suggested that change in attitude can be observed in locations where changes to future noise exposures have been forecast. Job et al. (1996) found that negative attitudes were higher in areas near the Sydney Airport in which an increase in noise was anticipated (by the authorities) and lower in areas where a decrease was anticipated. Schreckenberg and Meis (2007) reported that for the Frankfurt Airport, where a fourth runway was being planned, (mis)trust of the aviation industry was positively related to annoyance. However, both of these were cross-sectional studies before change occurred, not longitudinal evidence of attitudes changing systematically with changes in exposure. In fact, they provided no evidence that attitudes to the source/authorities actually 
changed, only that there was a difference in these attitudes in different areas (and for the Sydney data, a lack of clarity regarding their actual noise exposures) or at different levels of annoyance.

Houthuijs et al. (2007) provided data in which the link of these attitudes to change effects can be tested. A longitudinal study around the Schiphol Airport commenced a year before the planned opening of a new runway through three years afterward, with yearly repeated measures in a panel $(N=650)$ that was part of a large before-after survey of some six thousand respondents. They reported a systematic relationship between noise exposure and a composite measure of attitudes toward the airport and its expansion. Breugelmans et al. (2007) used the panel data from this study to analyze the role of changes in nonacoustical factors-including repeated measurements of attitudes to the authorities, the airport, and its expansion-reporting that the latter did not explain the excess response in the noise-increase subgroup of the panel. They concluded that the excess response can be considered to be a (change in) noise effect. Their model for repeated measurements included the noise level exposure $\left(L_{\mathrm{den}}\right)$ as well as the change in noise level (Delta $\left.L_{\mathrm{den}}\right)$, as predictors of response.

Despite strong evidence from Breugelmans et al. (2007) that changes in negative attitudes cannot explain observed excess response, the emphasis that has been given to this explanation in the past suggests that it should perhaps not be rejected at this stage without further confirmation

\section{Surrogate effect}

Reductions or increases in road traffic noise exposure may be associated with parallel changes in air pollution, congestion, accidents, housing value, presence of trucks, and general appearance of the area. Similarly, changes in aircraft noise exposure may be associated with changes in fear of crashes. The noise stressor will therefore change in association with change in many other stressors, and the combination may contribute to the observed change effects in noise response.

A credible mechanism for this explanation would be through these changes altering respondents' overall opinion of neighborhood quality - a known modifier in the exposureresponse relationship (Langdon, 1976). Vincent and Champelovier (1993) provided evidence of a quantitative increase in perception of neighborhood quality with the installation of a noise barrier, as did Öhrström (2004) following a major reduction in traffic flows. However, Griffiths and Raw (1989) did not find a difference in opinion of the area between newcomers (who had relocated to the area in the previous six years) and long-term residents who had experienced the change.

We suggest that this explanation be termed a surrogate effect, though a variety of terms has been used. Klæboe et al. (1998) explained excess response to traffic improvements in Oslo in terms of an areawide effect-simultaneous improvements in air pollution and volumes of road traffic amongst other factors (see also Klæboe et al., 2000). The Brown (2009) finding of a large excess response to noise in the major traffic improvement study by Öhrstöm (2004) could also be explained by the simultaneous improvements in other environmental factors as well as a change in noise exposure. A surrogate effect explanation would also fit the excess-response change effect reported by Kastka (1981). Horonjeff and Robert (1997) referred to Kastka's finding as a halo effect. The surrogate effect explanation remains a plausible mechanism to explain excess response.

\section{E. Demand-response bias generated by repeated questioning}

This explanation suggests that where panel designs involving repeat interviews of the same respondents are used, excess response may be an artifact of repeat interviewing. Repeat questioning may lead to demand-response bias or response set.

There is experimental evidence that demand-response bias does not occur in repeat measures of annoyance responses. Fields et al. (2000) analyzed a range of panel studies and concluded that they do not appear to introduce survey-resurvey bias in noise response, particularly if repeat surveys are at least 1 month apart. Jonsson and Sörensen (1973) noted work in which measurements on the same individuals on two occasions, and also on a control group on the second occasion, show no demand-response bias. Fidell et al. (1985) reported that after-change annoyance responses (for short-term annoyance) were similar over three repeat rounds of interviews (in what they regarded as being tantamount to a panel study) conducted over 3 months. They concluded that personal decision criteria for selecting annoyance response categories are stable over time and rounds of interviews (for relatively constant noise exposures) - a finding of no demand-response bias. These were the same data in which a reanalysis by Raw and Griffiths (1985) found excessresponse change effects-hence the latter was not an outcome of demand-response bias.

Job (1988b) noted that demand-response bias could be a particular problem where a panel is interviewed before and after the changes. Respondents are likely to feel that the interviewer is expecting (demanding) a changed reactionsuggesting any observed change effect would not be "genuine." However, Weinstein (1982) used a mixed panel design with repeat measures on the same respondents, supplemented by "one occasion" respondents - controlling for the possibility that initial contact with the panel group changes how it reacts. At 16 months after the change, the control group reported the same noise disturbance as the panel group. Fidell and Jones (1975) also found no difference in annoyance responses between a panel (interviewed three times by telephone before and after a change in flight paths at the Los Angeles airport) and independent control samples at the first and third interviews. The evidence suggests that demandresponse bias generated by repeated questioning is unlikely to be the cause of observed excess-response change effects.

\section{F. Adaptation-level theory}

The adaptation-level explanation hypothesizes that people who have been living in an area with high noise ex- 


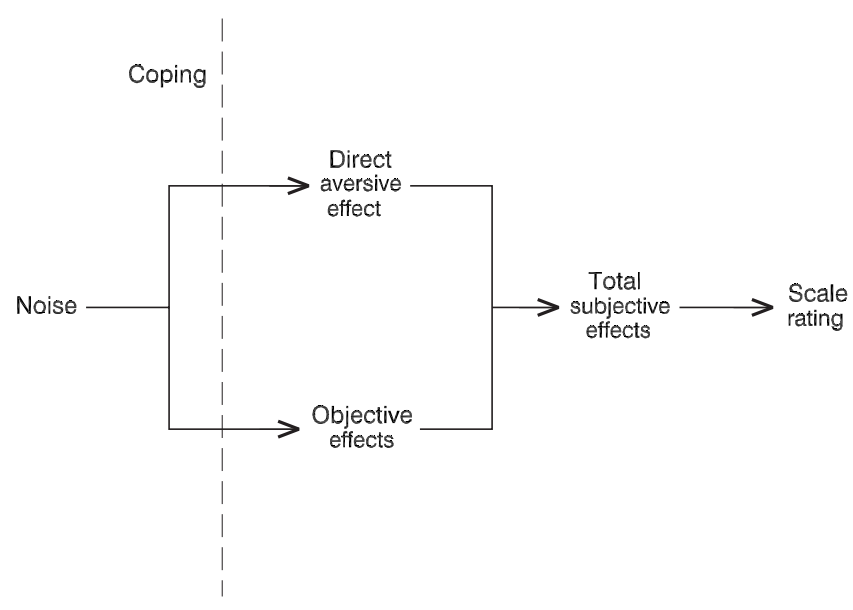

FIG. 2. The model for the retention of behavioral coping strategy explanation. Total subjective effects include direct aversive effect (annoyance) as well as activity interferences (objective effects), both filtered by coping strategies. (Source: Raw and Griffiths, 1990).

posures for some time change their expectation about the noise environment. Weinstein (1982), citing Helson (1964) and others, noted that there is a large body of research that people making perceptual judgments are influenced by the conditions to which they have been exposed previously, with their response to a stimulus a measure of the deviation of that stimulus from an optimal level of stimulation. This optimal level of stimulation is termed adaptation level. Respondents who are chronically exposed to high levels of noise would become desensitized to the exposure, experiencing reduced effects. While it could explain excess response in a singlesite study using retrospective assessments (Brown et al., 1985), it did not in studies where before and after measurements were used (Raw and Griffiths, 1990; Brown, 1987). Adaptation-level theory can be discarded as an explanation for excess response.

\section{G. Partial retention of behavioral coping strategies}

Raw and Griffiths (1990) proposed this explanation, observing that excess response is much less evident (see also Babisch and Gebhardt, 1986) in objective measurements of activity interference than in the subjective measurements of annoyance. To explain this, they formulated a set of hypotheses in which coping plays a key part. Figure 2 shows the total subjective effect defined to include direct aversive effect (annoyance) as well as activity interferences (objective effects), both filtered by coping strategies.

Raw and Griffiths (1990) provided evidence that when respondents experience a change in exposure, they change some of their coping strategies, in particular those "noise mitigating behaviors" such as closing windows or changing use of rooms, but partially retain them after the change. After a decrease in exposure, fewer people might keep their windows closed, but partial retention of this strategy would result in an excess effect in total subjective effects-coping appropriate to a previous higher exposure would result in lower than expected annoyance (compared to respondents who had always been exposed to the same low levels and who would not have applied coping strategies to the same

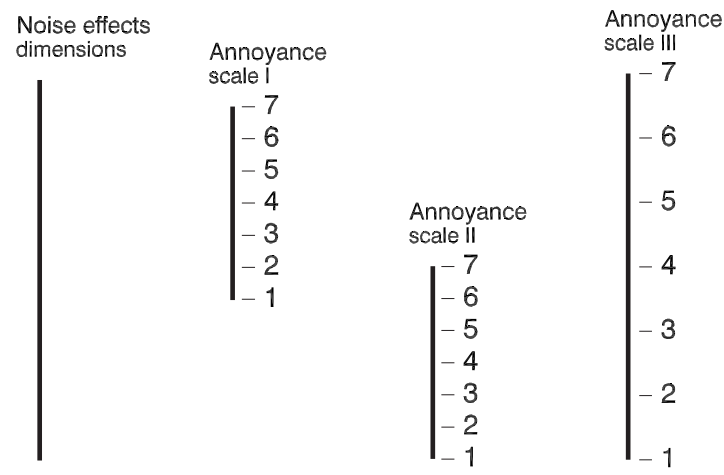

FIG. 3. The differential response criteria model suggests a different scaling of noise effects by respondents chronically exposed to high noise levels (annoyance scale I) and to low noise levels (annoyance scale II). After Brown (1987).

extent). The reverse would occur after an increase in exposure. Partial retention of behavioral coping strategies after a change would explain excess response in the annoyance scores, but Raw and Griffiths (1990) questioned why, over time, coping strategies would not continue to change to those appropriate to the new exposure, and the excess-response effect eventually disappears. They suggested, based on their evidence, that the relationship between objective effects of noise and total subjective effects is not constant before and after a change_objective effects (interferences) changed less markedly than subjective effects - and assumed that a relatively rapid sensitization to the increased noise stimulus (desensitization for a decrease in exposure) must occur. The retention of behavioral coping strategy explanation has not been subjected to further testing but, based on the limited evidence, remains a plausible explanation of the change effect.

\section{H. Differential response criteria for the annoyance scale (response bias)}

The differential response criteria explanation invokes a very different mechanism to that of the demand-response bias explanation - though often the literature on change does not differentiate these two bias mechanisms. This explanation was originally referred to as response bias (Brown, 1987) but differential response criteria is a better term. The differential response criteria explanation is a measurement error, distinct from the adaptation-level explanation, which required a real difference in sensory response to the stimulus.

The explanation requires the introduction of a "noise effect" dimension (as in the "total subjective effect" dimension of Raw and Griffiths (1990), Fig. 2). It suggests that annoyance rating scales might be used differently by respondents who are chronically exposed to different levels of steady-state noise exposure (Fig. 3) - scale I if they are chronically exposed to high levels and scale II if they are chronically exposed to low levels. Researchers invariably assume that response criteria for annoyance scales, or personal decision criteria (Fidell et al., 1985), are the same across all respondents irrespective of their exposure, but Berglund et al. (1975) demonstrated that response criteria for annoyance scales are not independent of the noise condition. 
The explanation suggests that when chronically exposed respondents experience a change, they may expand the annoyance scale to cover more of the range of the noise effect dimension, adopting postchange response criteria for the annoyance scale (say, scale III). After a reduction in exposure, the model suggests that change respondents might use scale III to scale their noise effects. They would thus report lower annoyance scores than would be reported by people chronically exposed to equivalent after-change levels. Both change respondents and chronically exposed respondents would be experiencing the same distribution of noise effects (as they are exposed to equivalent levels of noise), but the latter would scale these effects using scale II. A corresponding explanation applies to an increase in noise exposure-the model satisfactorily explaining change effects for both decrements and increments.

The logic of an ability to adjust scales according to experience is illustrated by a simple, but not trivial, example. Say, a person considered him/herself adversely affected by current long-term exposure (though only subject to moderate levels of noise) and, accordingly, responded to a presented annoyance scale with the maximum score. If this person were then to be subject to a significant noise increase (with consequent increase in noise effects), he/she would have no alternative, when presented with the same annoyance scale, but to respond again with a maximum score. The person's score has not changed, and this same score now represents greater noise effects on the individual (that is, noise effects have been scaled differently). A reviewer of this paper suggested that the person in this example illustrates an underreaction, not an excess-response, change effect. But such a conclusion is based on a different comparison-comparing the person's annoyance score after the change to that from before the change. The germane comparison for the differential response criteria explanation is of annoyance scores (after the change) of those who have experienced the change and annoyance scores (in the steady state) of people chronically exposed to equivalent after-change exposure levels. The latter yields an excess-response change effect.

This model was developed, post hoc, as a possible explanation of observed change effect in small studies of change in exposure (Brown, 1987; Brown et al., 1985). Its only subsequent testing was by Raw and Griffiths (1985), who suggested that the model was wanting in terms of explaining their own excess-response results. However, the mathematical analysis they adopted was flawed in their assumption of a constant and small range for the steady-state and postchange annoyance scales, not an expanded annoyance scale postchange (scale III in Fig. 3). Had their analysis not been limited in this way, the model would have fitted all of their empirical results.

The model may also explain why activity interferences may not display excess response as do annoyance scores. In contrast to the differential response criteria bias in the annoyance scores, self-reports of activity interferences can be expected to be the same for change respondents and chronically exposed respondents at the same level of exposure.

\section{Memory distortion}

A small number of change studies (Lambert, 1978; Brown et al., 1985; Mehra and Lutz, 2000) used retrospective assessment of before-change response to examine the effects of change. Raw and Griffiths (1990) noted that retrospective assessments cannot substitute for studies using carefully matched pairs, or experimental and control sites, in true before and after designs.

Retrospective assessments clearly have the disadvantage of possible memory distortion in reported effects. Two studies utilized both before and after measurements of response as well as retrospective assessment of before-change conditions. Brown (1987) found that respondents reported a very different distribution of annoyance scores before a change (increase) to what they reported, retrospectively, of their prechange condition. Lambert (1978) found that the mean retrospective-score of before-change conditions was slightly higher than the mean before-score, though only marginally so. In both studies, the sample size was small.

While retrospective data on before levels and post hoc self-reported adaptation can be considered as weak measures [self-reports of adaptation also potentially include memory distortion (see Sec. II A)], as most studies in which a change effect has been observed have not used retrospective assessments, they can be discarded as an explanation of the change effect.

\section{J. Self-selection}

This explanation suggests that it is only high noise level situations that receive interventions to reduce noise exposure (Baughan and Huddart, 1993), and studies of change that involve a decrease in noise are thus a biased sample of sites in the community. Fidell et al. (2000) and Mackie and Davies (1981) argued that people with high noise sensitivity will have already self-selected themselves out of such highly exposed sites. The self-selection explanation for excess response suggests that such movement will result in sites where respondents have lower average noise sensitivity. After a change to lower noise levels, these less vulnerable (that is, less noise sensitive) respondents will report much lower annoyance scores than predicted by exposure-response curves, resulting in a change effect (Weinstein, 1978; Evans et al., 1998).

However, a self-selection hypothesis requires that for a situation of unchanging high noise exposure, there should be a negative correlation between annoyance and length of residence. There is no evidence of this correlation. Weinstein (1982) indicated that the majority of noise studies have found no appreciable relationship between noise disturbance and length of residence, though the study of Griffiths and Langdon (1968) was an exception. Recent evidence of no self-selection effect can be found in Nijland et al. (2007). There is no convincing evidence supporting this explanation (Baughan and Huddart, 1993).

\section{K. Perceptual constancy}

Perceptual constancy or loudness constancy (Robinson et al., 1963; Langdon and Griffiths, 1982) suggests that 
TABLE I. Variables in the various change effect explanations. Subscripts B and A refer to conditions before and after the change in noise exposure. The total subjective effects of noise (AE) are not able to be measured directly.

\begin{tabular}{|c|c|c|c|c|c|c|}
\hline & \multirow[b]{2}{*}{ Exposure } & \multirow[b]{2}{*}{$\begin{array}{l}\text { Moderator } \\
\text { variables }\end{array}$} & \multirow[b]{2}{*}{$\begin{array}{l}\text { Behavioral } \\
\text { coping } \\
\text { strategies }\end{array}$} & \multicolumn{2}{|c|}{ Noise effects } & \multirow[b]{2}{*}{$\begin{array}{l}\text { Reported scores } \\
\text { (Annoyance scale } \\
\text { scores) }\end{array}$} \\
\hline & & & & $\begin{array}{l}\text { Interference } \\
\text { effects } \\
\text { (e.g., sleep } \\
\text { disturbance) }\end{array}$ & $\begin{array}{l}\text { Total } \\
\text { subjective } \\
\text { effects }\end{array}$ & \\
\hline $\begin{array}{l}\text { Before } \\
\text { change }\end{array}$ & $\mathrm{EXP}_{\mathrm{B}}$ & $\mathrm{MOD}_{\mathrm{B}}$ & $\mathrm{COP}_{\mathrm{B}}$ & $\mathrm{IE}_{\mathrm{B}}$ & $\mathrm{AE}_{\mathrm{B}}$ & $\mathrm{ANNOY}_{\mathrm{B}}$ \\
\hline $\begin{array}{l}\text { After } \\
\text { change }\end{array}$ & $\mathrm{EXP}_{\mathrm{A}}$ & $\mathrm{MOD}_{\mathrm{A}}$ & $\mathrm{COP}_{\mathrm{A}}$ & $\mathrm{IE}_{\mathrm{A}}$ & $\mathrm{AE}_{\mathrm{A}}$ & $\mathrm{ANNOY}_{\mathrm{A}}$ \\
\hline
\end{tabular}

people respond according to their perception of the source levels of the noise rather than to what they experience after the noise levels have been reduced through some path attenuation. For example, it suggests that they respond to levels of outdoor aircraft noise rather than to the lower levels that they actually experience indoors as a result of attenuation of the building envelope.

Perceptual constancy could explain why type 2 changes (noise levels reduced by building insulation or by barriers) may be different from type 1 changes (noise levels reduced by changes in the source) in terms of evidence of excessresponse change effects. Some authors (Langdon and Griffiths, 1982) refer specifically to this concept. Others, without using the term, have made related observations. Nilsson and Berglund (2006) noted that indoor annoyance was significantly reduced by the erection of a barrier though the effect of the barriers on the indoor sound levels was small, and Öhrström (2004) suggested that perception of noise and its disturbances outdoors contributes more to general annoyance reaction than indoor disturbances. Perceptual constancy remains a possible, though speculative, explanation for differences in change effects reported between type 1 and type 2 changes.

\section{DISCUSSION}

There is insufficient evidence to support a single theory, or explanation, of the change effect. Several of the explanations can be rejected based on a lack of supporting evidence, and several have been identified that warrant further consideration.

\section{A. Explanations rejected}

Adaptation/habituation is a convenient descriptor of a trajectory of response to change but has no value in the explication of a change effect. Even where described more formally in terms of adaptation-level theory, evidence that annoyance reactions do not diminish over time counts against this as an explanation for a change effect. There is also evidence that demand response resulting from repeated questioning of the same respondents in longitudinal panel surveys is unlikely to be the cause. Expectation has little support as a direct explanation of the change effect, though potentially may be associated with changing attitudes (if such attitudes actually change) before the noise exposure changes. There is no evidence for the self-selection hypothesis, and memory distortion can play no role where no retrospective judgments of response are utilized. Perceptual constancy may be a factor in explaining the difference in response effects resulting from type I and type II changes but not the excess response itself.

\section{B. Categorization of the remaining explanations}

The remaining four explanations fall into three categories based on distinctly different, but plausible, mechanisms:

- change effects resulting from a change in variables modifying the exposure-response relationship before and after the change,

- change effects resulting from measurement error in annoyance scales, involving a variable relationship between total subjective effects of noise and annoyance scores, and

- change effects resulting from the retention of behavioral coping strategies after a change.

While we distinguish between the different mechanisms, we do not discount the possibility, suggested by Baughan and Huddart (1993), that change effects may result from a combination of mechanisms.

\section{Change in variables modifying the exposure- response relationship between the before and after exposure conditions}

A range of nonacoustic variables that intervene in the exposure relationship for noise has been extensively measured, tested, and discussed in the literature (Schultz, 1978; Fields, 1993, 1994; Job, 1988a; Miedema and Vos, 1999, 2003; van Kamp et al., 2004). Under steady-state noise exposure conditions, these variables are regarded as constant. Or at least it is assumed that they are constant, given little suggestion to the contrary. However, two of the explanations suggest that this assumption needs to be revisited in situations where noise levels change.

For each of the attitudes to the source/authorities explanation and the surrogate effect explanation, variables that are known to intervene in the exposure-response relationship, attitudes toward the source and overall opinion of the neighborhood, respectively, could change in a change situation. As suggested in Table $\mathrm{I}$, where $\mathrm{EXP}_{\mathrm{B}}$ and $\mathrm{EXP}_{\mathrm{A}}$ are the noise exposure levels before and after a change, the values of 
$\mathrm{MOD}_{\mathrm{B}}$ may be very different from those of $\mathrm{MOD}_{\mathrm{A}}$, affecting the exposure-effect relationship differentially in the beforechange and after-change conditions and hence in the reported scores ANNOY.

\section{Changes in the relationship between effect of noise and self-reports of those effects}

The differential response criteria explanation suggests that annoyance rating scales might be scaled differently by respondents who have been chronically exposed to different levels of noise. Differences in response criteria represent a measurement error in steady-state responses that only becomes apparent where people have experienced a change in exposure. In Table I, this would be represented by a relationship between $\mathrm{AE}_{\mathrm{B}}, \mathrm{IE}_{\mathrm{B}}$, and $\mathrm{ANNOY}_{\mathrm{B}}$ different from that between $\mathrm{AE}_{\mathrm{A}}, \mathrm{IE}_{\mathrm{A}}$, and $\mathrm{ANNOY}_{\mathrm{A}}$. This explanation also suggests why change effects may appear in the reported annoyance scores (ANNOYs) but not in the interference effects (IEs).

\section{Retained coping strategies following a change}

In the terms of Table I, the retention of coping explanation suggests that the coping strategies that people develop at different levels of noise exposure (COP) may be retained to some extent after a change in exposure. The after-change coping $\left(\mathrm{COP}_{\mathrm{A}}\right)$ of those who have experienced the change will be different from the coping strategies of people chronically exposed to noise levels equivalent to the after-change levels.

\section{Newcomers versus long-term residents}

There is one matter still unresolved with respect to all of these explanations. If people change their attitudes and their coping behavior or adjust annoyance scales when noise levels change and if this is not a short-term phenomenon (and the evidence of persistence of change effects months and years after a change suggests that it is not), newcomers to an area following a change should report different annoyance responses from those who had lived there throughout the change. There is conflicting evidence. Griffiths and Raw (1989) reported that newcomers after a noise decrement were more annoyed than long-term residents who had experienced the change, and van Dongen and van den Berg (1983) found that a small group of newcomers after a noise increment was less annoyed than long-term residents. However, Klæboe et al. (1998) found that newcomers after a noise decrement were less annoyed than long-term residents-the opposite direction to that required by the explanations. Further longitudinal studies are necessary, which carefully compare the response of long-term residents who have experienced a change with those of newcomers.

\section{IMPLICATIONS OF THE EXPLANATIONS}

Our examination of different explanations for the change-effect phenomenon raises two larger but interrelated questions. First, should excess response to change be of concern to policy makers? And if so should it be addressed in environmental assessments of infrastructure projects? Sec- ond, are there implications of the different potential explanations of change effects to the interpretation of existing exposure-response relationships for transportation noise?

\section{A. Assessing change in exposure}

The evidence of the magnitude and the persistence, over time, of the change effect (Brown, 2009) and the existence of plausible explanations for it suggest that it is a real effect and needs to be taken into account in assessing the response of communities in situations where noise levels change. Within the limitations of existing evidence on change, communities that experience an increase in noise exposure are likely to experience greater annoyance than is predicted from existing exposure-response relationships, and communities that experience a decrease in exposure experience greater benefit than predicted. Policy makers need to be informed of these potential change effects, particularly as situations in which noise levels increase as a result of infrastructure changes are always likely to be contentious. To do otherwise would be to deny them important information regarding potential community response in these contexts. There is already one practical example of this (The Highways Agency, 2008). The change effect is not transient and is likely to be present until the normal turnover of residents in any particular community results in newcomers replacing those who experienced the change. This policy implication applies irrespective of which of the potential mechanisms - change in nonacoustical variables, differential response criteria, or retained copingmight explain the change effect. However, some of the explanations have additional implications.

\section{B. Implications for the interpretation of exposure- response relationships obtained in the steady state}

If changing attitudes to the source/authorities prove to be the explanation of the change effect, there is the potential for considered interventions to be used as an instrument to reduce noise annoyance of affected populations in situations of change. Transparent information/communication about the noise changes could positively affect attitudes and expectations of the community. Evidence of the existence of a change effect demonstrates that this should not be perceived merely as manipulative public relations, but a bona fide and positive contribution to managing the magnitude of the annoyance responses of the community subject to the change.

A differential response criteria explanation has much wider implications. It raises the question that there may be a measurement error across the generalized exposure-response curves. These are based on responses of people who have been exposed in the steady-state to particular noise levels. The explanation suggests that measurement error may be operational in all steady-state situations but is revealed only in situations of change. The consequence, from the direction of the change effect, is that the gradient of an exposureresponse curve adjusted for this purported error would be much steeper than that of currently used steady-state curves. There is a similar consequence arising from the explanation of changing attitudes. If attitudes of a group of respondents can collectively shift, in the manner required by this expla- 
nation in change situations, one cannot discount that the groups of respondents included in the surveys from which steady-state exposure-response curves have been derived might also have collectively shifted their attitudes, particularly those groups chronically exposed to high levels of noise. This is confounding as it would mean that exposureresponse curve baselines may already include in them, in part, the effect of these attitudes.

\section{Future studies of change}

This clarification of potential mechanisms provides a structure for the design of future studies of change. It provides guidance (Table I) as to what needs to be measured in longitudinal studies to overcome weaknesses in the existing set of studies/data in testing not only for the existence and durability of an excess-response change effect, but also for the various hypotheses to explain it.

The design of such studies will need to take into account that changes in nonacoustic factors may occur out of phase with the change in noise levels itself, potentially shaped by earlier announcements of infrastructure change (Job et al., 1996), public information and consultative/nonconsultative processes, and construction activities (Schuemer and Schreckenberg, 2000). All survey waves in longitudinal studies need to include adequate measurements of exposure, changes in exposure, responses, and changes in the appropriate nonacoustical variables. Babisch and Gebhardt (1986), as did Fields et al. (2000), suggested that panel studies would be strengthened by the addition of nonpanel respondents in the repeat surveys.

\section{CONCLUSIONS}

A wide range of explanations for excess response has been proposed. This review suggests that, while there is still no accepted and evidence-based view on a single mechanism that can explain the change effect, several of the explanations can be discarded on the basis of insufficient evidence, inconsistencies, or the inability to fit the limited empirical data available on response to change. The residual plausible explanations are grouped into three categories, each relying on a different mechanism to explain the change effect: changes in modifiers of exposure-response relationships in the context of change in exposure, differential scaling criterion for the annoyance scale at different levels of exposure, and retention of coping strategies following a change. There are significant policy implications of the change effect in terms of assessing human response in situations of change, irrespective of mechanism, and several of the mechanisms raise important questions regarding the interpretation of the exposure-response relationships based on steady-state surveys.

\footnotetext{
${ }^{1}$ Not to be confused with self-reported "noise sensitivity," which is generally regarded as an unvarying personal characteristic.
}

Babisch, W., and Gebhardt, S. (1986). "Gestortheitsreaktionen durch Verkehrslamr-Eine 'vorher/nachher'-untersuchung (Annoyance reactions caused by traffic noise-A 'before/after'-study)," Z. Lärmbek. 33, 38-45. Baughan, C., and Huddart, L. (1993). "Effects of traffic noise changes on residents' nuisance ratings," Proceedings of the Sixth International Congress on Noise as a Public Health Problem, Noise and Man '93, Nice, July, Vol. 2, pp. 585-588.

Bell, I. R., Hardin, E. E., Baldwin, C. M., and Schwartz, G. E. (1995). "Increased limbic system symptomatology and sensitizability of young adults with chemical and noise sensitivities," Environ. Res. 70, 84-97.

Berglund, B., Berglund, U., and Lindvall, Y. (1975). "A study of response criteria in populations exposed to aircraft noise," J. Sound Vib. 41, 33-39. Breugelmans, O., Houthuijs, D., van Kamp, I., Stellato, R., van Wiechen, C., and Doornbos, G. (2007). "Longitudinal effects of a sudden change in aircraft noise exposure on annoyance and sleep disturbance around Amsterdam Airport," Proceedings of ICA, Madrid, Paper No. ENV-04-002-IP. Brooker, P. (2008). "ANASE: Measuring aircraft noise annoyance very unreliably," Significance 5, 18-24.

Brown, A. L. (1987). "Responses to an increase in road traffic noise," J. Sound Vib. 117, 69-80.

Brown, A. L., Hall, A., and Kyle-Little, J. (1985). "Response to a reduction in traffic noise exposure," J. Sound Vib. 98, 235-246.

Brown, A. L. (2009). "Response to a change in transport noise exposure: A review of evidence of a change effect," J. Acoust. Soc. Am. (in press).

Djokvucic, I., Hatfield, J., and Job, R. F. S. (2004). "Experimental examination of the effects of attitude to the noise source on reaction and on reaction to performance," Proceedings of Internoise 2004, Prague, Paper No. 325.

Evans, G. W., Bullinger, M., and Hygge, S. (1998). "Chronic noise exposure and physiological response: A prospective study of children living under environmental stress," Psychol. Sci. 9, 75-77.

Fidell, S., Horonjeff, R., Mills, J., Baldwin, E., Teffeteller, S., and Pearsons, K. (1985). "Aircraft annoyance at three joint air carrier and general aviation airports," J. Acoust. Soc. Am. 77, 1054-1068.

Fidell, S., and Jones, G. (1975). "Effects of cessation of late-night flights on an airport community," J. Sound Vib. 42, 411-427.

Fidell, S., Pearsons, K., Tabachnik, B. G., and Howe, R. (2000). "Effects on sleep disturbance of changes in aircraft noise near three airports," J. Acoust. Soc. Am. 107, 2535-2547.

Fidell, S., and Silvati, L. (2004). "Parsimonious alternatives to regression analysis for characterizing prevalence rates of aircraft noise annoyance," Noise Control Eng. J. 52, 56-68.

Fields, J. M. (1993). "Effect of personal and situational variables on noise annoyance in residential areas," J. Acoust. Soc. Am. 93, 2753-2763.

Fields, J. M. (1994). "A review of an updated synthesis of noise/annoyance relationships," NASA Report No. CR-194950, NASA Langley Research Center, Hampton, VA.

Fields, J. M., Ehrlich, G. E., and Zador, P. (2000). "Theory and design tools for studies of reactions to abrupt changes in noise exposure," NASA Report No. CR-2000-210280, NASA Langley Research Center, Hampton, VA.

Fields, J. M., and Hall, F. L. (1987). "Community effects of noise," in Transportation Noise Reference Book, edited by P. Nelson (Butterworth, Washington, DC).

Flindell, I. H., and Witter, I. J. (1999). "Non-acoustical factors in noise management at Heathrow airport," Noise Health 1, 27-44.

Griffiths, I. D., and Langdon, F. J. (1968). "Subjective response to road traffic noise," J. Sound Vib. 8, 16-32.

Griffiths, I. D., and Raw, G. J. (1989). "Adaptation to changes in traffic noise exposure," J. Sound Vib. 132, 331-336.

Guski, R. (1999). "Personal and social variables as co-determinants of noise annoyance," Noise Health 3, 45-56.

Guski, R. (2004). "How to forecast community annoyance in planning noisy facilities," Noise Health 6, 59-64.

Hatfield, J., Job, R. F. S., Carter, N. L., Peploe, P., Taylor, R., and Morell, S. (2001). "The role of adaptation in responses to noise exposure: Comparison of steady state with newly high noise areas," Proceedings of the Fourth European Conference on Noise Control, Euronoise PATRA, January.

Helson, H. (1964). Adaptation-Level Theory (Harper \& Row, New York). Horonjeff, R. D., and Robert, W. E. (1997). "Attitudinal response to changes in noise exposure in residential communities," NASA Report No. CR-97205813, National Aeronautics and Space Administration, Washington DC, p. 150.

Houthuijs, D., Breugemans, O., van Kamp, I., and van Wiechen, C. (2007).

"Burden of annoyance dues to aircraft noise and non-acoustical factors," Proceedings of Internoise 2007, Instanbul, Paper No. 838472.

Job, R. F. S. (1988b). "Over-reaction to changes in noise exposure: The 
possible effect of attitude," J. Sound Vib. 126, 550-552.

Job, R. F. S. (1988a). "Community response to noise: A review of factors influencing the relationship between noise exposure and reaction," J. Acoust. Soc. Am. 83, 991-1001.

Job, R. F. S., Topple, A., Carter, N. L., Peploe, P., Taylor, R., and Morell, S. (1996). "Public reactions to changes in noise levels around Sydney Airport," Proceedings of Internoise 1996, Liverpool, UK, Vol. 5, pp. 2419 2424.

Jonsson, E., and Sörensen, S. (1973). "Adaptation to community noise-A case study," J. Sound Vib. 26, 571-575.

Kastka, J. (1981). "Zum Einfluss verkehrsberuhigender Maßnahmen auf Lärmbelastung und Lärmbelästigung (About the impact of traffic calming measures on noise levels and annoyance)," Z. Lärmbek. 28, 25-30.

Klæboe, R., Kolbenstvedt, M., Clench-Aas, J., and Bartonova, A. (2000) "Oslo traffic study-Part 1: An integrated approach to assess the combined effects of noise and air pollution on annoyance," Atmos. Environ. 34, 4727-4736

Klæboe, R., Kolbenstvedt, M., Lercher, P., and Solberg, S. (1998). "Changes in noise reactions-Evidence for an area effect?," Proceedings of Internoise 1998, Christchurch, New Zealand, pp. 16-18 (CD-ROM)

Lambert, R. F. (1978). "Experimental evaluation of a freeway noise barrier,' Noise Control Eng. 11, 86-94.

Lambert, J., Champelovier, P., and Vernet, I. (1996). "Annoyance from high speed train noise: A social survey," J. Sound Vib. 193, 21-28.

Langdon, J. (1976). "Noise nuisance caused by road traffic noise in residential areas: Part I," J. Sound Vib. 111, 243-263.

Langdon, F. J., and Griffiths, I. D. (1982). "Subjective effects of traffic noise exposure: II. Comparisons of noise indices," J. Sound Vib. 83, 171-180.

Lawson, B. R., and Walters, D. (1973). "The effects of a new motorway on an established /residential area," Proceedings of the International Conference on Environmental Psychology, University of Surrey, Guildford.

Mackie, M., and Davies, C. H. (1981). "Environmental effects of traffic change," TRRL Laboratory Report No. 1015, Transport and Road Rersearch Laboratory, Crowthorne, UK.

Maris, E., Stallen, P. J., Vermunt, R., and Steensma, H. (2007). "Noise within the social context: Annoyance reduction through fair procedures," J. Acoust. Soc. Am. 121, 2000-2010.

Mehra, S. R., and Lutz, C. (2000). "Berechnung und subjective Wahrnehmung der Lärmpegeländerung aufgrund einer neu erstellten Umgehungsstraße (Measurement and subjective perception of noise level changes due to a new roadway)," Z. Lärmbek. 47, 58-67.

Miedema, H. M. E., and Vos, H. (1999). "Demographic and attitudinal factors that modify annoyance from transportation noise," J. Acoust. Soc. Am. 105, 3336-3344.

Miedema, H. M. E., and Vos, H. (2003). "Noise sensitivity and reactions to noise and other environmental conditions," J. Acoust. Soc. Am. 113 1492-1504.

Ministry of Transport, Public Works and Water Management (2005). "Evaluatie Schipholbeleid: Schiphol beleefd door omwonenden (Evaluation Schiphol: Schiphol perceived by its residents)," Directorate-General Transport and Aviation.

Nijland, H. A., Hartemink, A., van Kamp, I., and van Wee, B. (2007). “The influence of sensitivity for road traffic noise on residential location: Does it trigger a process of spatial selection?," J. Acoust. Soc. Am. 122, 15951601.

Nilsson, M. E., and Berglund, B. (2006). "Noise annoyance and activity disturbance before and after the erection of a roadside noise barrier," J.
Acoust. Soc. Am. 119, 2178-2188.

Nimura, T., Sone, T., and Kono, S. (1973). "Some considerations on noise problem of high-speed railway in Japan," Proceedings of Internoise 73, Copenhagen, pp. 298-307.

Öhrström, E. (1997). "Community reactions to railway traffic-Effects of countermeasures against noise and vibration," Proceedings Internoise 97, Budapest, pp. 1065-1070.

Öhrström, E. (2004). "Longitudinal surveys on effects of changes in road traffic noise-annoyance, activity disturbances, and psycho-social wellbeing,"J. Acoust. Soc. Am. 115, 719-729.

Quehl, J., and Basner, M. (2006). "Annoyance from nocturnal aircraft noise exposure: Laboratory and field-specific dose-response curves," J. Environ. Psychol. 26, 127-140.

Raw, G. J., and Griffiths, I. D. (1985). "The effect of changes in aircraft noise exposure (Letter to the editor)," J. Sound Vib. 101, 273-275.

Raw, G. J., and Griffiths, I. D. (1990). "Subjective response to changes in road traffic noise: A model," J. Sound Vib. 141, 43-54.

Robinson, D. W., Bowsher, J. M., and Copeland, W. C. (1963). "On judging the noise from aircraft in flight," Acustica 13, 324-336.

Scholes, W. E. (1977). "The physical and subjective evaluation of roadside barriers," Proceedings of Internoise, pp. 144-153.

Schreckenberg, D., and Meis, M. (2007). "Noise annoyance around an international airport planned to be extended," Proceedings of Internoise 2007, Istanbul, Turkey.

Schreckenberg, D., Schuemer, R., and Moehler, U. (2001). "Railway-noise annoyance and 'misfeasance' under conditions of change," Proceedings of Internoise 2001, The Hague, Netherlands, Paper No. 344 (CD-ROM).

Schuemer, R., and Schreckenberg, D. (2000). "Anderung der Larmbelastung bei massnahme bedingter stufenweise veranderter gerauschbelastungHinweise auf einige Befunde und Interpretationsansatze (The effect of stepwise change of noise exposure on annoyance)," Z. Lärmbek. 47, 134143

Schultz, T. J. (1978). "Synthesis of social surveys on noise annoyance," J. Acoust. Soc. Am. 64, 377-405.

The Highways Agency (2008). Design Manual for Roads and Bridges, Volume 11, Section 3, Part 7, Traffic Noise and Vibration, http:// www.standardsforhighways.co.uk/dmrb/ vol11/section3/11s3p07.pdf (Last viewed April 7, 2008)

van Dongen, J. E. F., and van den Berg, R. (1983). "De gewenning aan het geluid van een nieuwe spoorlijn (Getting used to noise from a new railway line)," Report No. RL-HR-03-02, IMG-TNO, Delft.

van Kamp, I., Job, R. F. S., Hatfield, J., Haines, M., Stellato, R. K., and Stansfeld, S. A. (2004). "The role of noise sensitivity in the noise-response relation: A comparison of three International Airport Studies," J. Acoust. Soc. Am. 116, 3471-3479.

van Kempen, E. E. M. M., and van Kamp, I. (2005). "Annoyance from air traffic noise. Possible trends in exposure-response relationships," Report No. 01/2005, MGO Evk, RIVM, Bilthoven.

Vincent, B., and Champelovier, P. (1993). "Changes in the acoustic environment: Need for an extensive evaluation of annoyance," Proceedings Noise and Man '93, Sixth International Congress on Noise as a Public Health Problem, Vol. 2, pp. 425-428.

Weinstein, N. D. (1978). "Individual differences in reaction to noise: A longitudinal study in a college dormitory," J. Appl. Psychol. 2, 87-97.

Weinstein, N. D. (1982). "Community noise problems: Evidence against adaptation," J. Environ. Psychol. 2, 87-97. 